\title{
resot
}

Research in Social Sciences and Technology

\section{AN EXPLORATORY STUDY: MOBILE DEVICE USE FOR ACADEMICS}

\author{
Malia HOFFMANN, Ed.D \\ California State University, Fullerton \\ malia.csuf@gmail.com
}

\begin{abstract}
This exploratory study surveyed how undergraduate students and higher education instructors at two small faith-based universities in Southern California used mobile devices in and outside of the class for academic purposes. The researcher cross-referenced the results from the two groups to make correlations. The results of this study showed that nearly all instructor participants had multiple devices and almost half of the student participants had two or more devices as well. Those devices are being used in and outside of formal class for academics in very basic and emerging way that are just touching the surface of their capabilities. This study found that students use their devices in class to read, reference, or search materials. Faculty reported using their devices as presentation devices most often.

Key words: mobile devices, TPACK, formal learning, informal learning
\end{abstract}

\section{Introduction}

The popular Apple computer company has changed the educational landscape with the reinvention of traditional music players and basic cellphones, as well as the creation of advanced mobile devices, including the iPod Touch, iPhone, and iPad. Apple has inspired other companies like Google and Microsoft to reinvent cellphones, transform them into smartphones, and also create tablets. These devices, though used by individuals of all ages, have become quite popular on college campuses. According to the Pew Organization (Rainie \& Smith, 2013), 56\% of all American adults own a smartphone. Eighty percent of those adults who own smartphones are between the ages 18 to 29 years old. The undergraduate population that participated in this current study was within that age range. In addition to smartphones, e-readers and tablet 
computers have also become commonplace for Americans ages 16 and older, with 24\% owning those devices.

Undergraduate students appear to use their devices for more than just talking, texting, and social networking; these devices have also become tools for academic learning. Capitalizing on students' use of mobile devices could help lead educators to include these devices in their courses more deliberately. According to the Pew Institute (Rainie \& Smith, 2013), 34\% of all cellphone Internet users used their phones, rather than a desktop or laptop computer, as a primary tool to access the Internet. With these statistics in mind, it was apparent at the time of this study that there was much to be learned about the ways in which undergraduate students were using these devices for academic purposes. By uncovering the way students use academic mobile device, educators can begin to merge technological, pedagogical, and content knowledge (TPACK) practices into their pedagogical approaches (Koehler \& Mishra, 2008).

TPACK guided the theoretical framework for this study. TPACK builds on and expands Shulman's (1986) PCK (pedagogical and content knowledge) framework for teaching by adding the important technological piece that is so evident in today's learning environment. TPACK suggests best teaching practices to provide a blend of technological, pedagogical, and content knowledge into all courses. By providing an equal blend of each of the TPACK components, educators can establish rich learning environments for their students to keep them engaged while utilizing specific technologies and pedagogies that relate to their content areas.

Very few research studies have been done regarding the use of mobile devices in the higher educational environment. Additionally, none of those existing studies connected mobile learning to the TPACK framework. Therefore, the purpose of this exploratory study was to 
determine the mobile learning of undergraduate students and instructors and correlate the two groups' data. The correlated data gathered on both groups was connected with the TPACK framework to suggest pedagogical strategies for instructors to provide a richer learning environment that meets the needs and demands of today's mobile learners.

\section{Research Questions}

The following research questions were explored:

1. In what ways, if any, do undergraduate students use mobile devices in class for academic purposes?

2. In what ways, if any, do undergraduate students use mobile devices outside of class for academic purposes?

3. In what ways, if any, do higher education instructors use mobile devices for academic purposes in class?

4. In what ways, if any, do higher education instructors use mobile devices outside of class for academic purposes?

\section{Literature Review}

This study explored the ways in which college students and faculty used mobile devices: portable web-enabled devices for learning. The role of technology has changed the way people communicate with each other, which has also led to changes in support of students' learning. Pedagogical efforts and instructional theories were also considered when proposing mobile technologies for learning. TPACK connects technologies with specific pedagogical strategies (Koehler \& Mishra, 2008). Many qualitative and quantitative studies have been done on how young adults use technologies regularly. However, there is still much to be learned about how 
young adults use these technologies for academic purposes. Current non-academic uses and other mobile device studies, as well as TPACK studies, are discussed subsequently.

A meta-analysis of trends from mobile learning studies found that the key factors to define mobile devices were mobility and the ability to engage in educational activities without being tied to a location. Users are able to access wireless technology to access data, communicate, and mediate other educational activities $(\mathrm{Wu}, \mathrm{Jim} \mathrm{Wu}$, Chen, Kao, Lin, \& Huang, 2012). However, many users were not using the devices to their fullest potential. Being device centric, focusing on the device rather than the pedagogy in the devices' use, has hindered the ability to completely conceptualize the educational capabilities of those powerful mobile devices. Additionally, in a study conducted by Kilinc, Kilinc, Kaya, Baser, Turkuresin, \& Kesten, (2016) providing training for educators in areas of technology reduced anxiety and increased their beliefs and attitudes towards technology integration. Contrary to being device centric, using TPACK does not focus on the device; rather, it focuses on the full integration of technology into required content areas with appropriate pedagogies (Wu et al., 2012).

\section{Pedagogical Content Knowledge}

Shulman (1986) observed the focus of education on teachers' content knowledge in terms of teacher certification. Up until around 1986, teachers were to prove their knowledge of subject matters through tests, while never really needing to prove they understood pedagogical strategies to use with that content knowledge. He emphasized that both pedagogy and content knowledge needed to have shared importance when educating students. Too much focus on one or the other disrupted the necessary balance for students to learn accurately and effectively. If there was too much emphasis on the content knowledge but the teacher did not know how to convey those 
facts, the student would not learn. If the teacher was good at explaining content to students, varying their teaching techniques, but the content knowledge was wrong, then it still did not matter because the knowledge being taught was useless. Teachers needed to learn not just pedagogy itself, but also different pedagogical strategies in regard to different subject matter. Teaching should not be a one size fits all model. For example, science may require more hands on experiences like dissection, language arts requires peer-to-peer writers' workshops, and social studies may require utilization of primary source materials to enrich the learning environment. Shulman described this content-pedagogy connection as Pedagogical Content Knowledge (PCK), and it has changed the nature of teacher education in 1986 from that point forward.

\section{Development of Technological Pedagogical and Content Knowledge (TPACK)}

TPACK became relevant as a technology integration expert in higher education while considering how undergraduate professors can begin to integrate mobile devices into their formal instruction. Koehler and Mishra (2008) built upon and extended Shulman's (1986) theory of PCK to include technology integration. K-12 teachers have been pressured for about the past 2 decades, 1990-2014, to integrate technology. Higher education teachers have more recently begun to feel the pressure of technology integration; however, both groups of teachers have seen very few models that address how to accomplish this. Further more, as a country who is renowned for its technology and innovation; we still have a long way to go (Tarman, 2016). TPACK emphasizes teachers' knowledge because teachers are the biggest influences in the classrooms. In respect to the curriculum and standards, teachers have historically decided what would be taught and how it would be taught on a daily basis. Focusing on teachers' knowledge was the key place to start when looking at transforming classrooms. As new technology tools hit 
the stage like the iPads in 2010, some researchers posed questions regarding whether certain pieces of technology made a difference in the classroom, for instance, Do iPads influence learning? When realistically, the question that should be asked is, How do teachers use iPads to influence learning? Or, What subject matter instruction is enhanced by the use of iPads? The technologies used are irrelevant if the teacher is not equipped to use those technologies properly. Using the TPACK framework allows educators to look at equal distribution of focus on each of the core aspects of TPACK: Technological, Pedagogical, and Content Knowledge.

Teachers most commonly have used and are using combinations of Knowledge and any of the three core components of TPACK. Each component is equally important and equal distribution each of the components creates the best learning environment (Koehler \& Mishra 2008). Figure 1 taken from Koehler and Mishra (2008) demonstrates the combination of components of the TPACK framework.

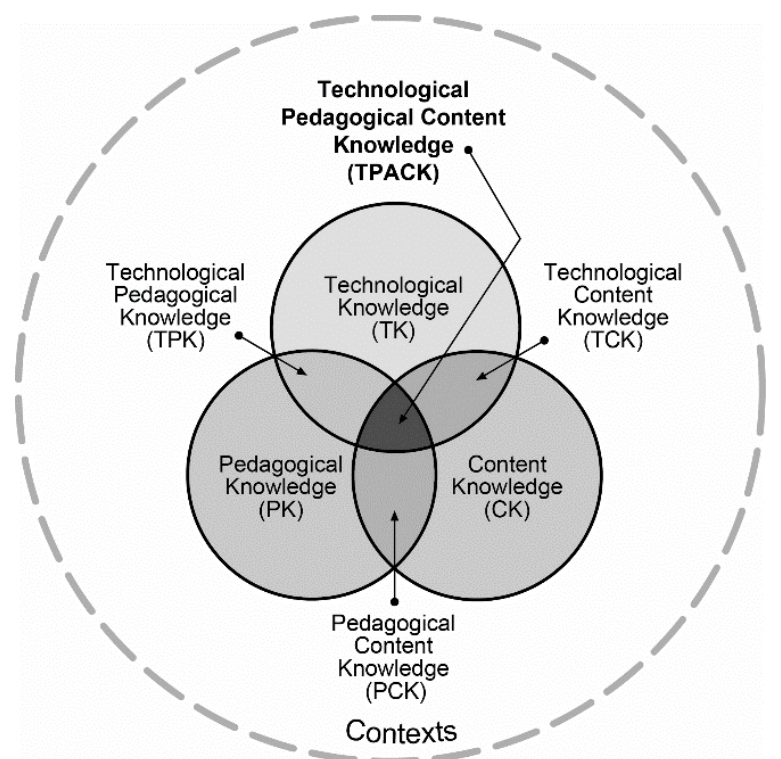

Figure 1. TPACK. Reprinted from Handbook of Technological Pedagogical Content Knowledge (TPACK) for Educators, p. 12, by M. J. Koehler \& P. Mishra, 2008. New York, NY:

Routledge/Taylor \& Francis Group for the American Association of Colleges for Teacher Education. Copyright 2008 by the authors. Reprinted with permission. 
Any combination of the three TPACK components with knowledge and the core components can exist. Content knowledge is the knowledge of the subject matter that is to be taught. Historically, higher education has been full of subject matter experts or individuals who are accomplished in their fields, hold much experience, and may even be well published. These individuals are known as content knowledge experts. Being a content knowledge expert is an important aspect of teaching because misrepresentation of content knowledge could impact students greatly (Mishra \& Koehler, 2006). Students have looked to their professors as the subject matter experts, and for the most part have accepted information given by teachers without question. If the content was misrepresented, it created holes in the students' foundational knowledge, impacting how they used that knowledge, creating the need for clarification of that knowledge down the road and further supporting the importance of content knowledge. Pedagogical knowledge is the educators' knowledge regarding how to teach, including educational objectives, students' evaluation, and learning processes (Mishra \& Koehler, 2006). Educators typically learn pedagogy through their teaching experiences and in their pre-service teaching programs. Knowing how to create lesson plans, vary instruction, and manage a classroom effectively demonstrate pedagogical expertise. Professors in teacher education programs are usually former teachers who have gained teaching or pedagogical expertise through teacher training and experiences. They then share this expertise with pre-service teachers (their students) to prepare those future teachers to prepare lessons, teach, and assess students appropriately. Solid pedagogy refers to how students viewed what were good teachers. This pedagogy can be demonstrated through differentiation of instruction and a strong sense of 
care for the students' education and well-being. Being an expert in pedagogy is what separates knowledgeable people from knowledgeable educators (Mishra \& Koehler, 2006).

Not only is it important to have a strong foundation in the content knowledge, but sound educators must also be experts in content pedagogy as well. Combining Content Knowledge and Pedagogical Knowledge creates a better learning experience for students. Educators who could do this effectively are able to choose appropriate teaching techniques and arrange the content so it can be best understood (Mishra \& Koehler, 2006). Often, educators who understand and apply Content Pedagogical Knowledge receive positive student evaluations. Students feel that the instructors are able to meet their diverse learning needs and create positive educational environments for them while further increasing their content knowledge. For instance, when teaching mathematics, a teacher might pose meaningful questions related to what the students know. A teacher who is sound in his/her content knowledge and Pedagogical Knowledge will be able to find errors in students work and suggest corrections. The instructor will not only know math concepts, but also be able to adapt the instruction to meet the students' needs (Mishra \& Koehler, 2006).

Technological Knowledge is the knowledge someone has regarding technology tools, whether analog (books and/or whiteboards) or digital (Internet, tablet applications, and/or web 2.0 tools; Mishra \& Koehler, 2006). Technological knowledge is always changing since technologies are always changing. With that in mind, it is difficult to define technological knowledge due to its state of flux. Becoming computer literate is a skill that an educator holds with the ability to stay flexible and apply knowledge across platforms or tools, making an educator knowledgeable in technology (Koehler \& Mishra, 2008). Educators who have 
technological knowledge are able to troubleshoot technology on their own or with little to no direction or support. Individuals with sound technology knowledge do not require a lot of direction and they also have a large repertoire of tools to use. However, possessing technological knowledge alone does not make an effective educator (Mishra \& Koehler, 2006).

Teachers are blending Technological Knowledge and Content Knowledge when they find or create connections between content areas and technologies. An expert teacher in this regard would be able to find tools that connect to the core subject areas, for instance using Geometer's Sketchpad for teaching mathematics. Technological and Content Knowledge teachers are able to replace tasks that were done without technology and provide technologies to achieve those same learning objectives (Mishra \& Koehler, 2006). For example, rather than have a teacher provide a lecture on Newton's laws of physics, he/she might provide interactive games or use web 2.0 tools to teach the same content.

Technology teachers are usually strong in Technological and Pedagogical Knowledge and are able to choose the right technologies for the learning objectives at hand. Such an educator understands and demonstrates different teaching strategies and varies the uses of technologies. An expert in this area is able to find a variety of tools for a variety of instructional uses (Mishra \& Koehler, 2006). He/she is able to adapt to and stay up to date on the latest trends in technology, educational and otherwise. Rather than take an analog task and rework it with technology, this type of teacher will use technology as a tool to make that learning project better. For example, studying Newton's Laws of Physics again, an instructor could have students digitally record gravity at work by dropping two different weighted items at once, and have the students slow the recording down to re-watch to see if the heavier object drops first or 
at the same time. The key to technological and pedagogical knowledge is the diversity in tools and strategies that the teacher implements. The technology is the tool, not the purpose (Mishra \& Koehler, 2006).

Finally, Technological Pedagogical and Content Knowledge is the ideal blend of all four components. It requires a full understanding of each area and how to use and apply each of the core components. TPACK applies a variety of technologies that represent concepts and facilitate pedagogical techniques to differentiate teaching (Mishra \& Koehler, 2006). An educator who incorporates TPACK effectively is able to build on students' prior knowledge by including appropriate technologies and best pedagogical practices. The incorporation of all three components, Technological Pedagogical and Content Knowledge, blends technology seamlessly into the classroom. TPACK applies to the technology teachers and their courses as well as the subject matter instructors. The teacher does not use technology for its own sake, but rather has an educational purpose, and is able to find several different applications of those tools. An effective TPACK integrating educator is able to model this framework in instruction daily and provide an integrated teaching approach to meet the diverse needs of all learners (Mishra \& Koehler, 2006).

\section{Timeliness of this Study}

Today, higher education is under the microscope and being investigated more closely to reform the educational stage and make changes. The working world demands that today's students create and research, not just consume information. The Higher Education Academy (HEA) challenges universities to work harder to make connections between teaching and researching (Kukulska-Hulme, 2012). With the rise in popularity of MOOCs, questions have 
been raised about the need for or purpose of funding a traditional 4-year education. Mobile devices have been evolving quickly; however, the instructional strategies in higher education have not been evolving as fast (Cruz-Flores \& Lopez-Morteo, 2010). Many K-12 institutions are working diligently to create technology rich learning environments for their students, not to mention the large amount of money that schools are investing in technological devices and educational materials (Kilinc et al., 2016). However, as mentioned previously, once students graduate and go to college, they go back in time with regard to technology integration. Traditional higher education institutions are falling behind with regard to progressive education, and now they must be forced to make changes or they will lose students to more innovative forms of education like MOOCs. Mobile device integration is one progressive change that higher education institutions must begin to recognize that students are demanding.

Although students use their devices on their own, they could benefit more if their instructors would find deliberate uses for these powerful technologies. Ally $(2004,2009)$ found that students used their mobile devices for both simulation and explorative information retrieval. However, students required some assistance from instructors to guide them away from misconceptions while searching the web for answers during information retrieval using devices. Additionally, when students were given devices rather than using their own technology, students experienced more difficultly because they were using unfamiliar technologies and instructional time was lost (Chang, Chatterjea, Goh, Theng, Lim, Sun, \& Nguyen, 2012). If students have devices, they know how to use them; teachers merely need to ask them to do a task and the students will know what tool to use to accomplish it. Educators do not need to be experts in devices; however, getting involved in the learning process with those tools will create better 
learning environment where both student and teacher will benefit. With mobile device implementation educators will not feel as though they are fighting the potential distraction of mobile devices and students will feel empowered and guided to use these powerful devices. Traxler (2010) discussed the attitudes of today's undergraduate students, noting that mobile devices:

Affect people's sense of time, space, place and locations their affiliations and loyalties to groups and communities, the ways in which they relate to other individuals and to groups, their sense of their identity, and their ethics, that is their sense of what is right, what is wrong, what is approved of and what is inappropriate. They bring these attitudes into the universities. (p. 2)

How students connect and learn with others has changed dramatically. What students know and how they know it is no longer something that is only obtained from sitting in a classroom or reading out of a textbook. The gathering of information has become more attainable and immediate. Rather than going to class or to the library, students can get answers within seconds on their own devices. Mobile devices afford learners the portable ease to learn on the go, while providing motivation for both teaching and learning (Korkmaz \& Yurtseven, 2016). Students no longer require the assistance of a professor or personally known expert in order to ask questions or make connections. Rather, students can now send a tweet into the Twitterverse and receive answers within minutes. These answers can be validated by the masses since they are posted publicly. Students can utilize a variety of other resources within communities or other like-minded learners (Kukulska-Hulme, 2010). Learning is now experienced and supported in digitally mediated environments (Bell, 2011). This immediacy and ease of access to information 
is changing the landscape of higher education. Learning no longer needs to be confined to four walls and a professor; rather it is social, interactive, 24/7, and immediate.

Learning is more than just processing content; social learning theory emphasizes the importance of the context in which information is received (Bandura, 1971). Students need to learn through observations, direct instruction, and social experiences. A variety of experiences to reinforce the content are needed for students to conditionalize that information. Mobile devices afford students opportunities to engage in the content socially as often as needed. Mobile devices provide more mobility to learning, providing students with necessary social learning experiences.

This study is timely due to the high pressure on higher education intuitions to offer something relevant to today's mobile learners. With the rise in MOOCs that provide opportunities for free education to the masses, higher education institutions must work hard to provide a unique and personalized learning experience. K-12 schools are setting the standards for rich technology environments, yet when students arrive on college campuses their use of technologies diminishes drastically. Using TPACK will provide a sound framework to take the focus off of the particular devices and focus on an equal blend of all the important components of learning to meet the digital demands of today's students.

\section{Methods}

The researcher chose two similar research sites to triangulate the data. Students and faculty were recruited from two small religiously affiliated liberal arts universities in Southern California. Both locations had undergraduate and graduate programs. For this study, the researcher only investigated traditional undergraduate students and instructors who taught at least one class a semester. A convenience sample was taken from the two universities due to the 
researcher's accessibility and ties to those university sites. According to University A statistics gathered in the Fall of 2014, University A had 1,592 traditional undergraduate students, 373 of whom were new freshman (first-time first-year degree seeking students). Of those 373 freshmen, 40 were part-time. Males made up $40.7 \%$ of the population and females made up $59.3 \%$. Demographically, the traditional undergraduate population included 54 (3.39\%) non-resident aliens, 307 (19.28\%) Hispanics/Latinos, 3 (0.19\%) American Indians/Alaska Natives, 85 (5.34\%) Asians, 49 (3.08\%) Blacks/African Americans 6 (0.38\%) Native Hawaiians/Other Pacific Islanders, and 807 (50.69\%) White. The population included 71 (4.46\%) students identifying with two or more ethnicities, and 210 (13.19\%) students of unknown ethnicity. Seventy-one percent of undergraduate students required financial aid assistance.

University B had 3,474 traditional undergraduate students. Males made up $42.8 \%$ of the population and the females made up 57.2\%. Demographically, the traditional undergraduate population included: 16.5\% Hispanics/Latinos, 0.6\% American Indians/Alaska Natives, 13.5\% Asians, 7.4\% Blacks/African Americans, 0.5\% Native Hawaiians/Other Pacific Islanders, and 49.2\%) White students. The population included 5.3\% students identifying with two or more ethnicities, and $6.9 \%$ students of unknown ethnicity. Eighty-one percent of students utilized financial aid.

Many of the same questions that were asked of the students were used for the faculty survey. The instructors were asked about reasons for not including mobile devices; that question was based on research done by Terras and Ramsay's (2012), which found that many faculty members abstain from mobile device usage due to potential student distractions. Ifenthaler and Schweinbenz's (2013) work informed this survey's option of too many obstacles to overcome to 
integrate tablets. Koehler and Mishra's (2008) research informed the survey's option of too much time spent needing to learn the technological knowledge. This survey used current research on educators' reluctance to integrate technology to inform its available options.

\section{Data Analysis Methods}

Multiple-choice data were analyzed with descriptive statistics; answers to open-ended items and comment boxes were coded using rubrics that went through several iterations.

Rubric creation for open-ended items. Eight of the 12 questions had open-ended comment sections. Rubrics were used to make sense of those. The following sections list the questions asked of the participants followed by the rubrics to code those responses. Students' questions and answers are listed first followed by the questions asked of the instructors and their answers.

\section{Findings}

\section{Part 1: Descriptive Analysis Results}

This first section of the findings section will review descriptive analysis results from the most relevant survey questions. The second section of the chapter will use those analyses to answer the research study questions.

Students: What are some reasons you are using mobile devices? (check as many as apply). The student participants were asked to check all that apply for the reasons they were using mobile devices. Table 1 reflects those responses in order from most common the least common reasons for using mobile devices. Thirty-seven participants responded to this question. Four student participants checked other and wrote answers such as check the time, GPS, to communicate when I'm away on debate or internship trips, and for distraction in class! 
Table 1

Students: What Are Some Reasons You Are Using Mobile Devices? (Check as Many as Apply)

\begin{tabular}{lc}
\hline Reason & $n$ \\
\hline Make it easier to access my work & $31(84 \%)$ \\
Increase my communication with other students & $29(78 \%)$ \\
Increase my communication with my instructor & $23(62 \%)$ \\
Increase my efficiency with tasks & $20(54 \%)$ \\
Collaborate with others & $20(54 \%)$ \\
Increase my knowledge in my field of study & $17(46 \%)$ \\
Make it easier to complete my course work & $16(43 \%)$ \\
Turn in assignments & $11(30 \%)$ \\
Improve my quality of work & $10(27 \%)$ \\
Quiz or Poll & $9(24 \%)$ \\
Increase my motivation toward completing my coursework & $8(22 \%)$ \\
Other & $4(11 \%)$ \\
\hline
\end{tabular}

Note. $N=37$.

Instructors: What are some reasons, if any, you are using mobile devices? (check as

many as apply). Table 2 reflects responses to this question in order from most common to least common reasons for using mobile devices. Seventeen participants responded to this question.

One participant checked other and wrote, Still learning!

Table 2

Instructors: What Are Some Reasons You Are Using Mobile Devices? (Check as Many as Apply)

\begin{tabular}{lc}
\hline Reason & $n$ \\
\hline Increase my communication with students & $12(71 \%)$ \\
Make it easier to access my instructional materials & $11(65 \%)$ \\
Increase my efficiency with tasks & $10(59 \%)$ \\
Increase my motivation in students & $9(53 \%)$ \\
Increase my communication with colleagues & $9(53 \%)$ \\
Improve my quality of instruction & $6(35 \%)$ \\
Increase my knowledge in my field of expertise & $5(29 \%)$ \\
Increase collaboration for my students & $4(24 \%)$ \\
Quiz or Poll & $4(24 \%)$ \\
Podcasts/Vidcasts & $3(18 \%)$ \\
Give assignments & $3(18 \%)$ \\
Other & $1(6 \%)$ \\
\hline
\end{tabular}


Note. $N=17$.

The most common responses between students and instructors for using mobile devices were to increase communication, easier access to school materials or information, and efficiency with tasks. This finding indicates that both students and instructors have the same goals for using mobile devices and these could be shared with other students and instructors.

Student and instructor uses in class. This section presents the questions asked of students and instructors regarding the way in which the participants used mobile devices in class.

\section{Instructors: Do you ever ask your students to use mobile apps to complete}

assignments? Yes: Tell me about a time when you did. Fourteen of the 19 respondents said no and six of the 19 responded with yes. Collaboration, Special Purpose Applications, Campus App/LMS, Flipping, and Consumption/Reference/Search were the codes used to group the responses, which are listed from most commonly used to least commonly used in Table 3.

Table 3

Instructor: Do You Ever Ask Your Students To Use Mobile Apps to Complete Assignments?

\begin{tabular}{lc}
\hline Response & $n$ \\
\hline Collaboration & $2(33 \%)$ \\
Special Purpose Application & $2(33 \%)$ \\
Campus App/LMS & $2(33 \%)$ \\
Flipping & $1(17 \%)$ \\
Consumption/Reference/Search & $1(17 \%)$ \\
\hline
\end{tabular}

Note. $N=6$.

It is interesting that there was a disparity between the student and the instructor responses. The common themes between the two groups are Collaboration, Special Purpose Apps, and Campus Applications/LMS. The other responses that students gave were more student-centered, like taking notes, which fit into productivity and reading. However, students 
reported taking quizzes on their devices, yet no instructors reported asking students to take quizzes online. Perhaps instructors see those quizzes as part of the LMS and not an outside application.

Students: Name a few mobile apps that you use inside of class. Thirty-six students responded to this question; of those 36 , three said none. One student specifically said, I almost never use my phone in class (too distracting), if I do I use Safari or Adobe to pull up an article during class discussion or Google (for definitions or thesaurus). The responses fit into nine different categories - Consumption, Campus/LMS, Productivity, Cloud Storage, Special Purpose Apps, Social Media, Communication, Entertainment, and Games. Table 4 reflects the number of student participants who reported using the corresponding category of mobile app in class.

Table 4

Students: Name a Few Mobile Apps That You Use Inside of Class

\begin{tabular}{lc}
\hline App & $n$ \\
\hline Consumption & $16(44 \%)$ \\
Campus/LMS & $10(28 \%)$ \\
Productivity & $9(25 \%)$ \\
Social Media & $6(17 \%)$ \\
Communication & $6(17 \%)$ \\
Cloud Storage & $5(14 \%)$ \\
Special Purpose Apps & $5(14 \%)$ \\
Entertainment & $2(5 \%)$ \\
Games & $2(6 \%)$ \\
\hline
\end{tabular}

Note. $N=36$.

Instructors: Name a few mobile apps, if any, that you ask your students to use in your

classes. Seventeen instructors responded to this question; of those 17, five said none (or they do not ask students to use mobile apps). The responses fit into eight different categories: Consumption/Searching, Educational Streams/Entertainment, Social Media/Video 
Conferencing/Communicating, Campus/LMS, Special Purpose Applications, Collaboration, Cloud, and Quizzing/Polling. Table 5 lists the responses in order of most commonly requested applications to least commonly requested applications.

Table 5

Instructors: Name a Few Mobile Apps, If Any, That You Ask Your Students to Use in Your Classes

\begin{tabular}{lc}
\hline App & $n$ \\
\hline Consumption/Searching & $6(35 \%)$ \\
Educational Streams/Entertainment & $5(11 \%)$ \\
Social Media/Video Conferencing/Communicating & $3(18 \%)$ \\
Campus/LMS & $3(18 \%)$ \\
Special Purpose Applications & $3(18 \%)$ \\
Collaboration & $3(18 \%)$ \\
Cloud & $1(6 \%)$ \\
Quiz/Poll & $1(6 \%)$ \\
\hline
\end{tabular}

Note. $N=17$.

Common uses between students and instructors were Consumption/Searching, Social Media, and Campus/LMS uses, which indicates and supports the earlier claims that instructors ask students to use mobile devices to look up information or check for references. Social media may be used as a means to connect with other students or experts in the field. Finally, many students and instructors are utilizing their schools' LMSs. Some students are aware of Cloud storage applications, yet instructors are not asking their students to utilize them for easier access to course materials. Additionally, instructors reported asking students to use applications for collaboration, but students are not reporting using those. Collaboration applications such as Google Drive, which could double as Cloud storage, could help students communicate with each other, aid productivity, and well as increase engagement, addressing the concern of the student 
who mentioned the potential distraction of using mobile devices for learning. If these uses are encouraged and directed by instructors, students may have less chances to be distracted.

\section{Students: Tell me about a time when an instructor has explicitly asked you to use a}

mobile device. Thirty-one responded to this question; four of those 31 said none, which means that instructors have not asked the students to use a mobile device. The coded responses fit into the following categories: Reference/Search, Quiz/Poll, Campus/LMS, Communication, Productivity, Photography, Calculate, and Educational Streams. The responses are listed in Table 6 in the coded categories from most commonly asked to use to least commonly asked to use.

Table 6

Students: Tell Me about a Time When an Instructor Has Explicitly Asked You to Use a Mobile Device

\begin{tabular}{lc}
\hline Purpose & $n$ \\
\hline Reference/Search & $14(45 \%)$ \\
Quiz/Poll & $7(23 \%)$ \\
Campus/LMS & $3(10 \%)$ \\
Communication & $3(10 \%)$ \\
Productivity & $2(6 \%)$ \\
Photography & $2(6 \%)$ \\
Calculate & $1(3 \%)$ \\
Educational Streams & $1(3 \%)$ \\
\hline
\end{tabular}

Note. $N=31$.

Instructors: Tell me about a time when, if at all, you used asked your students to use a mobile device in your class. Sixteen instructors responded to this question; of those 14, two said none or have not (asked students to use a mobile device in class). The responses fit into five different categories: Research, Collaboration/Communication, Polling, Special Purpose Applications, and Campus/LMS. The number of instructors who responded within those coded responses are reflected in Table 7, from most commonly asked to least commonly asked. 
Referencing was rated the highest among both groups, which indicates a very basic use of a mobile device as a reference tool, no different than asking students to look in their book for an answer. Campus/LMS uses and Communication were also rated highly.

\section{Table 7}

Instructors: Tell Me About a Time When, if at All, You Used Asked Your Students to use a Mobile Device in Your Class

\begin{tabular}{lc}
\hline Purpose & $n$ \\
\hline Research & $7(44 \%)$ \\
Collaboration/Communication & $5(31 \%)$ \\
Polling & $3(19 \%)$ \\
Special Purpose Applications & $3(19 \%)$ \\
Campus/LMS & $1(6 \%)$ \\
\hline
\end{tabular}

Note. $N=16$.

\section{Part 2: Research Questions Answered}

This section of the chapter will use the aforementioned analyses to answer the research questions.

\section{Research question 1: In what ways, if any, do undergraduate students use mobile}

devices in class for academic purposes? This study showed that students and instructors are at very basic use of mobile devices. Those mobile technology uses do not utilize technology specific uses. The mobile device uses that students reported could just as easily be done with analog tools such as books or papers, students reported using their devices in class for finding information, reading, consumption, reference, search, and distraction. Before the digital age students would have referenced encyclopedias. Nowadays, they reference Wikipedia. They could have referenced their textbooks; today they may have that textbook digitally. The benefit of the mobile device for these basic uses is the speed with which the information can be obtained. 
Using the search feature within an eBook application like iBooks or Kindle, students can quickly pull up the desired information, whereas before, students would have had to rely on their memory of where the information was, bookmarks, or notes. Mobile devices allow users to more quickly and efficiently gather the information that in the past would have taken more time. Students noted distractions as well. They stated that they were not bored, but got distracted while looking up content. Other students in the study specifically stated that they were aware of the potential for distraction and chose not to use their devices for that reason.

Communication, collaboration, social media, and Cloud storage can be accomplished in a unique with mobile devices. The first smartphones' main purpose was to communicate via text, call, or email. Today, smartphones have the power and the enhanced ability to communicate beyond those basic uses and open doors to collaboration, cloud storage, and social media, which can add tremendously to the learning experience. Students can edit a document or project simultaneously using Google Drive. They can share it with each other via the same means or store and share files to be accessed easily at any time through cloud storage tools like Dropbox or Evernote. Social media allows students to crowd source information, connect with experts, and obtain data, facts, or resources within seconds. The power of information through social media in real time is unique through the easy access of mobile devices.

Finally, tools like campus apps/LMSs, special purpose apps, photography, entertainment, games, calculating, and educational streams put mobile device usage a cut above laptop or analog tools. Application developers specifically design apps for users to create, collaborate, share, and explore. When students or educators use these advanced features or applications of mobile devices it reflects a deeper knowledge of the TPACK framework. Students can take 
photos of notes on a whiteboard to reference later quickly and easily. They no longer have to diligently copy everything down and worry that they got it right; they have the exact image to reference. Calculating apps can perform the most advanced calculations without needing a specific type of graphing calculator; students can buy a graphic calculator app for much less than what they would spend on such a device. Campus applications or LMSs allow students to access necessary and pertinent course content at anytime, anywhere. That content is personalized to their course needs. Educational streams and entertainment apps allow students to access lectures, podcasts, vidcasts, and related multimedia content without ever having to leave their seats. Finally, games, although initially thought of as a distraction by many, have academic qualities if connected correctly to the content. For example, Angry Birds can be connected to physics and Clash of the Clans can be used to develop problem solving and team building strategies. All of these applications can be done best with mobile devices, due to their ease of portability and specific application features, taking learning to the next level.

\section{Research question 2: In what ways, if any, do undergraduate students use mobile} devices out of class for academic purposes? Similar to the ways students used devices in class, Consumption, Reference, Search, and Productivity were used outside of class for academic purposes. Reading was not listed as an activity done outside of class on mobile devices. This is interesting because it could mean that students also buy the physical books but do not carry them to class, hence referencing their mobile devices in class. Productivity was a surprising finding here because many students stated that it was easier to produce work on a computer rather than a mobile device. 
Music, Entertainment, Social Media, Communication (email, text messaging, and/or chats), Shopping, Cloud Computing and/or cloud, and Storage were some of the uses students noted outside of class. Music and entertainment was also reported; students reported listening to or watching music/ entertainment while doing schoolwork. Social media and communication were reported as means to connect with classmates regarding what assignment due dates or to collaborate on assignments including cloud storage and computing applications. Students indicated that they shop on sites like Amazon to purchase textbooks or other school resources.

Games, Special Purpose Apps, Navigation, and Campus App/LMSs, again are unique to mobile devices. Some of these uses, like games, were noted as a means to regroup between homework sessions. Special Purpose Apps, like Epocrates, allow medical students to make informed medical decisions by referencing studies or experts in the field. Campus App/LMSs are used both in and outside of formal class for different purposes. Students simply reference those apps in class, whereas outside of class students use them to hand in assignments and participate in discussion forums.

\section{Research question 3: In what ways, if any, do instructors use mobile devices in class}

for academic purposes? Many instructors reported using mobile devices for Presentation, Consumption, Reference, Search, Educational Streams, and Entertainment. Again, these are very basic uses of the devices that can be accomplished on a computer or even through the use of a TV, DVD player, etc. These methods do not encourage TPACK usage; rather, they are just another way of doing what they have already been doing. The ease of access can be argued here for searching and referencing as well as timely access to educational streams if a situation arises, but generally, these uses are not mobile device specific. 
Some faculty noted using mobile devices in class for Collaboration, Cloud access, Conferencing/Communicating, and Quizzing/Polling. These uses are taking mobile learning to the next level. Instructors are not necessarily utilizing the mobile devices to their fullest potential, yet they are well on their way to doing so. Some of these functions can be performed on laptop devices; however, with their increased ease of access, mobile devices make these uses timely. Collaboration through tools such as Google Drive or Prezi allows creation of dynamic content in seconds while including all students. Cloud access allows instructors to provide all students access to electronic documents without ever having to make a photocopy or leave the room. Conferencing and communicating could that were once done solely via telephone can now be done with smartphones, Skype, FaceTime, or Google Hangout. Viewers can not only hear but also see the other person in real time. This affordance opens many doors to connect with experts in the field across great distances without ever leaving the campus. Finally, quizzing or polling allows teachers to get obtain time formative assessment data from every student to ensure everyone is learning. Since every student in this study had access to a smartphone, mobile devices have the potential to allow instructors to require every student to participate in the means they see appropriate.

Special Purpose Apps, Campus App/LMS, Flipping the classroom, Social Media/Videos utilize the unique features of mobile devices. Professors are able to find content specific applications like the TWEN application, which allows law students to access archives and law specific information; an activity that would have had to be done in a library only years ago. Flipping the classroom can be done easily through the use of the video camera on a mobile device so that class time can be used in more collaborative and interactive ways. Social media 
and videos allow instructors to access current content within seconds and connect it with what is being taught or discussed. It allows instructors to personalize each class, rather than teach from a script. Finally, campus apps or LMSs allow instructors to personalize learning for their students, make changes as necessary, and meet the diverse needs of each student through posting a variety of content.

\section{Research question 4: In what ways, if any, do undergraduate instructors use mobile} devices out of class for academic purposes? It is evident that faculty do more research with their mobile devices outside of class than in class, whereas students used their devices in class for researching more often than outside of class. Faculty reported using mobile devices to access Books, Educational Streams, News, and to Communicate, Produce documents etc., and Reference. Mobile devices make it easier to accomplish these tasks; however, mobile devices are not essential to the accomplishment of these tasks.

Social Networking, Music, and Cloud Based Apps are beginning to use the full capabilities of mobile devices. Faculty can use social networks to connect with their students outside of class to answer questions or provide resources. Mobile devices allow this to happen outside of the office or home. Cloud Based Apps allow documents to be shared easily and accessed from any device, providing the most up to date information. Music was noted as more of a form of entertainment while working on academic content.

Campus App/LMS, Photography, Games, Navigation are uses that take advantage of the advanced features of mobile devices. The Campus Apps/LMSs allow for rich content to be shared and personalized for students to access at any time. Photography allows faculty to capture specific examples of course connected content. Games can be created to make learning more 
dynamic and potentially connecting and capturing the interest of their students. Navigation can be used to connect a setting to the context of course materials. These advances mobile devices uses seem to be more for instructors' personalized learning rather than for their students; however, these uses can be developed and encouraged use in class with their students as well.

\section{Summary of Findings}

The study revealed that students use their mobile devices for a wide variety of tasks. Many of those uses were in fact academic in class; however, a few non-academic themes did emerge. Two students outright reported using their devices to distract themselves. They stated: Used my smartphone to remove some boredom during lectures, and used it to text or look at Instagram, not necessarily because class was boring, just couldn't resist. Other write-in answers of ways they used their devices in class included entertainment, social media, games, and communication. However, social media, games, and communication uses can also be academically related. Specific non-academic examples included Family Guy, SnapChat, and Texts. This distraction potential was a major concern for instructors and contributed to their apprehension about integrating mobile devices into their course. However, out of 38 students who responded, only two explicitly admitted to using it as a distraction, whereas seven other students acknowledged the potential distraction and noted the following reasons for not wanting to use a mobile device in class: (a) It's easy to get distracted, so many apps, (b) it gets distracting, (c) I get distracted easily, (d) mobile devices 100\% distract me from school work, (e) will use them for other purposes and distracts other students who handwrite notes, (f) laptop is not as distracting a phone, and (g) gets easily distracted with other things on the laptop or tablet. 
However, if instructors are guiding and deliberately integrating devices into their courses, students will be less likely to get distracted.

It is important to acknowledge that distractions do not come from the devices; rather, distractions are a problem with the pedagogy. Whether a student has a device or not, if he/she is not engaged he/she will find a distraction. Students used to pass notes or talk to their neighbors; now mobile devices offer a different medium for distraction. It is not the device that is inherently distracting. Focusing on engaging pedagogical strategies while including mobile devices may begin to utilize the TPACK framework while dispelling the notion that devices are to blame.

Both students and instructors shared a few advanced or unique mobile device uses: collaboration, quizzing/polling, and special purpose apps. However, these uses were reported as being teacher directed, or as formal learning. These uses do not reflect the TPACK framework because the pedagogical strategy is recalling information, nor is the technological application unique to the pedagogical approach. Recalling information can be done just as easily through analog tools as it is through this technological application. The key with TPACK is to not simply substitute analog for digital; rather, it is to provide a rich technological application that supports the pedagogical strategy.

Collaboration uses reported by both students and instructors were at an emerging level passed simply consuming and/or referencing. Dropbox, Prezi, Google Drive, and virtual notebook were some examples of collaborative uses. Dropbox was noted as a place to share files. Sharing files can also be accomplished through Google Drive or Evernote as well. It is not just the sharing of files that is important, but also the ability to collaborate in real time on those files. The power of Google Drive allows collaboration to occur simultaneously with changes in real 
time. Additionally, each member of the group can have access to the documents. Pedagogically, instructors can have group members keep organic chemistry notes together without anyone needing to make a copy or physically get together. TPACK strategies are being utilized through encouraging students to do active learning while using technology and collaboration.

Some of the pedagogical strategies that faculty members mentioned included appropriate teaching methods regarding the PCK model. For instance, many students reported that faculty ask them to use their devices to look something up or reference material. Teachers are asking students to learn through inquiry, discovery, or active learning. However, just because they use a mobile device instead of a book does not make this task TPCAK. In the sciences a professor may ask student to search for the symptoms of a specific disease; doing so while utilizing a mobile device's unique features would align this task with the TPACK framework. An educator could still implement the active learning model by using mobile device communication features to connect with experts, arrange interviews, harness the power of live social media to obtain public opinion on a topic, or use Instagram to search hashtags of images. Changing this way of thinking for instructors needs to happen in order to move toward true TPACK integration.

The biggest potential is for TPACK integration with mobile devices is the integration of special purpose applications such as VoiceThread, which allows easy collaboration while taking advantage of the presence of mobile devices. By using VoiceThread in history courses, instructors can model TPACK teaching strategies. VoiceThread connects with the New York Public library, allowing students to locate primary source materials. Students may also comment on their classmates' work via voice, type, or video. This application utilizes a variety of technological knowledge teaching strategies. Additionally, applications such as Nearpod (allows 
students to follow the instructor, collaborate, work at their own pace, etc.), Notability (robust note taking through images, audio, and text as well as collaboration capabilities), or Geometer's Sketchpad (geometric drawings with hands on capabilities to measure segments, angles, etc.) are all good examples of uses toward using the TPACK framework effectively. These are just a few more advanced mobile device applications instructors could use that participants failed to mention in the study. The aforementioned applications encourage TPACK integration into the college classroom. With instructor directed use of these tools, students may begin to use them on their own outside of class to accomplish informal learning. With teacher directed uses of mobile applications, students will be less likely to be off task or distracted as well.

\section{Limitations}

The results of this study are best applied to other universities with similar demographics and populations. Information about participants was obtained through self-report measures; therefore, the results may reflect personal uses that are not demonstrative of the entire university populations' usage. The researcher pulled a random sample from each research site to provide a representative population sample. The sample of research subjects was limited to those who consented to participate in the study and were students who attended two small Christian liberal arts universities in Southern California. The intent of surveying a random sample was to obtain a cross section of the population to provide the most accurate view of the universities' student populations. The researcher adapted the student survey instrument that was used by researchers from UCF (Chen \& DeNoyelles, 2013) to incorporate the most up to date research data. The student and faculty surveys were piloted before the start of the data collection. Two experts in the educational technology field validated those pilot study survey results. Data collection was 
limited to the time allowed by the Institutional Review Board (IRB). The researcher gathered data over the course of 6 weeks during in-session semesters to best capture the participants' uses of mobile devices for academic purposes. 


\section{REFERENCES}

Ally, M. (2004). Using learning theories to design instruction for mobile learning devices. In J. Attewell \& C. Savill-Smith (Eds.), Mobile learning anytime everywhere (pp. 5-8). London, UK: MLearn.

Ally, M. (2009). Mobile learning: Transforming the delivery of education and training. Edmonton, Alberta, Canada: AU Press.

Apple. (n.d.). Apple press info: iPod + iTunes timeline. Retrieved from http://www.apple.com/pr/products/ipodhistory/

Bandura, A. (1971). Social learning theory. New York, NY: General Learning Corporation.

Bell, F. (2011). Connectivism: Its place in theory-informed research and innovation in technology-enabled learning. International Review of Research in Open and Distance Learning, 12(3), 98-118. Retrieved from http://www.irrodl.org/index.php/irrodl

Chang, C., Chatterjea, K., Goh, D., Theng, Y., Lim, E., Sun, A., \& Nguyen, Q. (2012). Lessons from learner experiences in a field-based inquiry in geography using mobile devices. International Research In Geographical \& Environmental Education, 21(1), 41-58. doi:10.1080/10382046.2012.639155

Chen, B., \& deNoyelles, A. (2013, October 7). Exploring students' mobile learning practices in higher education. Educause. Retrieved from http://www.educause.edu/ero/article /exploring-students-mobile-learning-practices-higher-education 
Cruz-Flores, R., \& Lopez-Morteo, G. (2010). A framework for educational collaborative activities based on mobile devices. International Journal Of Interactive Mobile Technologies, 4(3), 9-18. doi:10.3991/ijim.v4i3.1268

Ifenthaler, D., \& Schweinbenz, V. (2013). The acceptance of tablet-PCs in classroom instruction: The teachers' perspectives. Computers in Human Behavior, 29(3), 525-534. doi:10.1016/j.chb.2012.11.004

Kilinc, E., Kilinc, S., Kaya, M., Baser, E., Turkuresin, H., \& Kesten, A. (2016). Teachers’ attitudes toward the use of technology in social studies teaching. Research in Social Sciences and Technology, 1(1), 59-76.

Koehler, M. J., \& Mishra, P. (2008). Handbook of technological pedagogical content knowledge (TPACK) for educators. New York, NY: Routledge/Taylor \& Francis Group for the American Association of Colleges for Teacher Education.

Korkmaz, U. \& Yurtseven, Z. (2016). Turkish pre-service teachers’ experiences with contemporary technology games and perceptions about teaching with instructional games. Research in Social Sciences and Technology, 1(1), 44-58.

Kukulska-Hulme, A. (2010). Learning cultures on the move: Where are we heading? Journal of Educational Technology \& Society, 13(4), 4-14. Retrieved from http://www.ifets.info

Kukulska-Hulme, A. (2012). How should the higher education workforce adapt to advancements in technology for teaching and learning? Internet and Higher Education, 15(4), 247-254. doi:10.1016/j.iheduc.2011.12.002 
Mishra, P., \& Koehler, M. J. (2006). Technological pedagogical content knowledge: A framework for teacher knowledge. Teachers College Record, 108(6), 1017-1054. doi:10.1111/j.1467-9620.2006.00684.x

Rainie, L., \& Smith, A. (2013, October 18). Tablet and e-reader ownership update. Retrieved from http://www.pewinternet.org/2013/10/18/tablet-and-e-reader-ownership-update/

Shulman, L. (1986). Those who understand: Knowledge growth in teaching. Educational Researcher, 15(2), 4-14. doi:10.3102/0013189X015002004

Tarman, B. (2016). Innovation and education. Research in Social Sciences and Technology, 1(1), 77-97.

Terras, M. M., \& Ramsay, J. (2012). The five central psychological challenges facing effective mobile learning. British Journal of Educational Technology, 43(5), 820-832. doi:10.1111/j.1467-8535.2012.01362.x

Traxler, J. (2009). Current state of mobile learning. In M. Ally (Ed.) Mobile learning: Transforming the delivery of education and training (pp. 9-24). Edmonton, Alberta, Canada: Athabasca University Press.

Traxler, J. (2010, January). The "learner experience” of mobiles, mobility and connectedness. Paper presented at ELESIG Symposium: Digital Futures, Reading, UK. Retrieved from http://cloudworks.ac.uk/cloud/view/3472

Wexler, E. (2014). What are teens doing online? Retrieved from http://www.pbs.org/wgbh /pages/frontline/media/generation-like/what-are-teens-doing-online/ 
Wu, W. H., Jim Wu, Y. C., Chen, C. Y., Kao, H. Y., Lin, C. H., \& Huang, S. H. (2012). Review of trends from mobile learning studies: A meta-analysis. Computers \& Education, 59(2), 817-827. doi:10.1016/j.compedu.2012.03.016 